\title{
Brief Analysis on Cultivation of Basic Professional Skills of Students of Fashion Show in Colleges and Universities
}

\author{
Li Wan \\ Huanghe Science and Technology College \\ Zhengzhou, China, 450005
}

\begin{abstract}
Through the analysis on the basic professional skills of students majoring in fashion show from colleges and universities, this paper concluded that it is the most significant task to improve the basic professional skills for the students majoring in fashion show with along the rapid development of economic integration in Central Plain. The analysis of the prerequisite demand for the basic professional skills of students offers guidance for the educational work of the fashion show major in colleges and universities in Henan Province.
\end{abstract}

Keywords-colleges and universities; fashion show; professional skills

Fashion show is a new major of higher education and is an exclusive subject in our country. This major aims to cultivate qualified fashion performing personnel with the ability of performing fashion show, designing image and costume and managing the costume. They are supposed to work as fashion models, to arrange and organize fashion show, to design costume and manage the costume after graduation. With the rapid development of clothing industries, the clothing display requires increasingly higher demonstration of cultural connotation. Thus, there is a new standard for modeling. Models are no longer the tools for showing the clothes but a group of professional personnel who are educated, cultured. Then the fashion show, as an undergraduate major, comes into being.

Huanghe Science \& Technology College has been opening fashion show major for ten years since 2004. Reviewing ten year's experience of teaching, we come to the conclusion that the combination of teaching for basic skills and professional features is the most important task for the training of professional modeling talents. The special of this major requires higher vocational ability than the academic ones. Therefore, we should integrate the education of academic capability the professional skills.

Thus, this thesis induces and analyzes the prerequisite basic skills for fashion show major.

Fund project: The "Research on Building Basic Ability for Occupation in The Education of Fashion Show in Our Province" - the research topic of Henan Association of Social Sciences and Henan Federation of Economic Organizations in 2013, with project No.: SKL-2013-2472

\section{ACQUiRING BASIC KNOWLEDGE CONCERNING WITH COSTUME ART}

\section{A. Understanding Theme of Clothing}

Theme of clothes is the spirit and value orientation of the work which is abstract and recapitulative ones presented as the form of clothes. Lifestyle clothes designs emphasis beauty and practical while artistic costumes are designed to show dreams and stories. Sentiment is the foundation for both of them. Theme of the clothes is often neglected due to its glaring appearance. Thus, models need to analyze and understand theme of the costumes in order to be professional. They have to surpass feeling provide by image and dig deep into the art concepts. Abstract attainment is the requisite skill for the expression of specific and ocular works. These are usually the weak points of models and the aspects that need much attention during the educating process of fashion show majors.

Theme of the clothes can be divided into three categories:

First, themes contain emotional feelings. This kind of clothes carries strong psychological characteristics, such as a special sentiment or normal emotion. These emotions have explicit positive or negative tendencies. However, the emotion is a blur intrinsic or expressive need. For a lot of cases, costume designers cannot express their intensions clearly after they devise their works under the stimulation of an instant emotion. In this circumstance, models are supposed to motivate their thoughts, develop their understanding toward the work of art and come up with the action and feeling for showing this understanding. It is normal that different model have diverse views toward works of this theme. As long as the perform shows profound meaning, it is successful.

Second, themes reflect ideological trends. This kind of theme of clothes has intense social characteristics and usually unequivocal. It shows general social concepts through the code of costumes. Conversely, it is the results of costume designation influenced by the general social concepts. A foreign designer once designed an evening dress called "A midsummer night's dream" with flowing yarn which leaves the shoulder and back uncovered. The designer tries to convey a night-filled poetic feeling. This work requires models to use their body language and posture display skills to express the 
hazy and vacant atmosphere of this piece of work.

Third, a genre of clothes represents specific meaning. It is featured as representative and not analyticity. This kind of clothes has explicit themes that require understanding the main idea. The structure, pattern and style represent clear meanings that can be comprehended directly. For example, at the conference of Northeastern mandarin formal attire display, many costumes explicitly expressed the theme of "combining ancient and modern style, blending eastern and western culture". Most models did excellent during the presentation.

Models frequently confuse theme of clothes with title of the performances during the shows. Nevertheless, these are different things with same points. Theme is the designation concept of a series of clothes while title is the conclusive words for the common feature of different series of clothes showed in the performance. Although title is related to specific style of the clothes, it is relatively macroscopic. For instance, a costume display title as "so young" must provides the overall experience of vivacious, young and vulgar. However, theme of sportswear and school uniform should be different.

\section{B. Understanding Aesthetic Factors of Clothing in Terms of Form}

In terms of form, the basic aesthetic factors of clothing are shape, color and quality. The shape, with rational characteristics and distinctive characteristics of free sketching, grasps the essential factors of clothing designing from point, line to area. Whereas the color has the sensibility characteristics with realism, the color can be depicted from three physical characteristics of color, namely hue, lightness and fineness. Apart from the physical characteristics, the color has psychological characteristics, such as changes in temperature, light or heavy, changes in distance, advance or retreat, soft or hard and etc. And the quality has strong regulation with physical characteristics. We regard the clothing as a kind of visual art. This is not an absolutely exhaustive proposition since the quality, as one of the aesthetic factors of clothing in terms of form, can be palpable from both vision and touch. In other words, the visual effect of the quality is transformed from the touch. The different qualities of clothes with the same black color will generate different effects. The silk fabrics make people feel graceful and gorgeous, the black wool fabrics calm and elegant, and the black cotton and linen fabrics grave and solemn. If the fashion models can grasp these basic formal elements of clothing, they can not only try to figure out the artistic characteristics based on their instincts, but also can have the sense to analyze the modeling to the works spontaneously.

\section{Understanding of Performance Costume}

To the fashion models, the most important task before the performance is to understand the theme of the costume. Although the performance is a process of "external-oriented", its aim is "internal-oriented". The performance aims to imply something, which means the whole process, based on the costume performance, pays more attention to the audience's feelings. Consequently, the new feelings will be generated. Thus, the performance is a visual art based on the costume and beyond it. The fundamental cause of so many performances showing different costumes in the same fashion without changes in styles is the fashion models cannot understand the characteristics of the costume.

Fashion models should take the static costume from the view of the sense of movement. The dynamic and static situations of one costume will bring about absolutely different visual effects. The dynamic one is more emotional. It is because the dynamic costume is more emotional that the dynamic one has more emotional intensity. If the emotional aim of the dynamic one is not predesigned, the performance is prone to being aimless. Therefore, the fashion models must understand the costume and understand the performance form. It is beneficial to the models to understand the costume if they have more opportunities to try on different styles of clothing.

\section{To Have Solid Basic Skills to Show Your Figure}

\section{A. Figure Management}

Fashion models should do shape-up exercise from getting into this industry, which requires self-management and self-control of your body shape. Doing shape-up exercise can not only keep the model in a high rate of metabolism, improve organs' function and strength the model's physique, but also better the body shape as plans and make the body shape well-proportioned, coordinate and beautiful, which results in a better performance of the body motion on a T-shaped platform.

The shape-up exercise is one of the important parts of fashion show skills. Even you have a good body shape and a good sense of costume, it is impossible to be a professional model without systematic modeling body shape training. The basic physique training course is the first class to the professional model.

In most cases, a fashion model's physique training course mainly concludes warm-ups, aerobic exercise, cool down exercise, gentle activity, basic posture exercise and part shaping exercise.

Apart from the physique training, the excellent fashion model should know the diet control and the relationship between the physique training and the nutritional diet. Thus, the models should strictly control and manage their figures.

\section{B. Catwalk and Posture Training}

Fashion show, as a lively human body art, is a way to demonstrate modern people's body language ability. Mien, catwalk, modeling, manner, expression in models' eyes and facial expression in the fashion show results from refined life and feelings in synthetic times. Walking is the most fundamental motion posture factors. Catwalk includes the motion posture factors of walking legs, swinging arms and etc. Catwalk is the basic motion posture factor in the fashion show. The motion posture factors, such as catwalk, modeling and etc, constitute a set of motion factors units in which the aesthetic significance is generated.

It can be drawn a conclusion from the artistic form and structure in the fashion show that the catwalk is a fundamental factor in model's body language. All the changes in modeling are based on the catwalk. Usually people choose a 
comfortable way to walk, but the model takes elegance as the priority. Catwalk, the important structural factor, links the costume performance modeling motions. The earliest catwalk was greatly influenced by dance. At that time, models almost performed with dance moves. Nowadays, the catwalk performance is completely a lifestyle, but the dance moves, occasionally as a complementary, will generate a better effect in modeling. In addition, an excellent model should thoroughly familiar with the pace, route and modeling gesture of the catwalk.

\section{Marketing AND PlanNing ABILITy}

\section{A. Marketing Ability}

In the market economy era, an excellent fashion show talent should have marketing and public relation ability. Since models have comparatively short career time, they have to lay a solid economic foundation in order to attain the career peak in a short term and to find another opportunity available for self-development. Therefore, it is important for the fashion show talents to have the marketing and public relation ability which is the basic professional skill to be mastered. Thus, the fashion show major is associated with marketing in many colleges and universities, such as the following majors "automobile marketing and model art" and "fashion show and marketing". From the name of the majors, we can clearly know the relationship between the model and marketing. However, fashion show major in Henan Province has not connected the fashion show with marketing. Personally, even the name of the major will not be altered, it is better to add some courses concerned with marketing into the curriculum in order to strengthen students' basic ability in the marketing field.

\section{B. Organizing and Planning Ability}

A qualified fashion show talent meeting with the market demand needs to have outstanding organizing and planning ability. As the fashion show, in essence, is a kind of dissemination and promotion activity, it certainly should follow the general communication rule. Knowing the communication theory, elements and rule of fashion show is the basic skill to improve organizing and planning ability. Only if the models have the ability to organize and plan, then they can broaden their employment channels and they can be qualified to work in some industries concerning with fashion, organization and plan. And they can even do better than the people who don't have the experience of being a model. Hence, from the employment point of view, students from fashion show major should also have organizing and planning ability which is one of the necessary basic skills they should master.

\section{OTher BAsic Professional ABILITIES}

\section{A. Good Mental Quality and Mental State}

Models with good mental quality are popular in the industry. They can leave a good impression on others and they can broaden their own employment channels at the same time.

Taking model as a profession is arduous. The profession will make you have a dry skin on your face, make skin of your face allergic to something and get pimples on your face because you have to wear a lot of make-up and to stay up for working frequently. You have to use a great deal of hair spray for having different hairstyles and to comb the hair backward, which can result in a tousled hair. Even the hair has to be cut out since the hair is too tousled to be combed. Models will put on heavy headwear making them hardly lift their heads, wear heavy clothes and high-heeled shoes making their feet painful. All the above things you do will make you difficult to walk. However, you should not complain anything since you are a model and a professional model needs a good mental state.

When people's subject wishes are contradictory to objective reality, they will have a negative emotional reaction. As an excellent model, when you encounter unhappy things, you should know how to control your emotion and keep good mental state. Firstly, you have to get a hold of yourself with consciousness and to remind yourself to be with reason. Secondly, you should tackle with things appropriately. Do not deal with things in haste. Moreover, try yourself to stand in others' shoes and to be tolerant. At last, keep smiling and happy. It is easy to be affected by others' emotion. If you smile at others, other people will bring their happiness to you.

\section{B. Good Etiquette Cultures}

\section{1) Punctuality}

As a professional model, you should be punctual. Punctuality is a protocol to respect others. Firstly, the model's work needs cooperation from a team. If one of the team members is late, every member's work will be postponed. Sometimes being late will also cause more trouble. In addition, if a model is not punctual, it can produce a negative influence on their career development.

\section{2) Personal Condition}

As a professional model, you should always be ready for work. Therefore, you should keep in good condition from head to heel and this is the basic etiquette skill a model should master.

A professional model must pay frequently attention to their skin and hair care. A female model should take off her hairs in the area of armpits, legs, arms and bikini and a male one should do shaving, trim his mustache and nose hairs and keep himself clean.

Apart from the external care, the internal health can reflect personal condition. Models should work out regularly, use appropriate fitness ways to lose unwanted fat and create a perfect body curve. They should be on a regular diet, scarcely ingest high-fat foods, eat fruits and vegetables and drink water frequently and take moderate amount of vitamins as supplements. If there are no requirements from the work, they should go to bed early and get up early, do not stay up, do not smoke and do not drink too much.

In this opportunity of rapid development of the Central Plain economic integration, clothing industries in Henan Province are developing more rapidly. Fashion show industries are closely related with the clothing industries. Thus, fashion show majors from colleges and universities are facing opportunities and challenges. In addition, as the competition of all walks of life is increasing, only having 
solid foundation of the professional basic skills can students majoring in fashion show meet different occupational demands from various industries upon graduation.

\section{REFERENCES}

[1] Liu Yuanjie, Theoretical Foundation of Fashion Show [M], Hong Kong, China Culture Publishing House, 2010.

[2] Zhu Huanliang, The Foundation of Fashion Show [M], Beijing, China Textile Press, 2012.

[3] Xiao Bin, Zhang Jian, Introduction to Fashion Show [M], Beijing, China Textile Press, 2010.

[4] Guo Jialan, Gu Ping, Bai Jing, Fashion Show Training and Directing [M], Chongqin, Southwest China Normal University Press, 2011.

[5] Li Yufei, Yang Yongqing, Fashion Show and Its Planning [M], Beijing, China Light Industry Press, 2010.

[6] Xu Qingqing, Fashion Show· Planning· Training [M], Beijing, China Textile Press, 2006.

[7] Bao Mingxin et al., Fashion Show Art [M], Shanghai, Donghua University Press, 2005.

[8] Zhang Jian, Behind the T Stage: Fashion Director's Note [M], Beijing, China Textile Press, 2005. 